\title{
Perioperative risk factors predict one-year mortality in patients with acute type-A aortic dissection
}

Yanwei Yang ${ }^{1,2 \dagger}$, Jiayi Xue ${ }^{2,3+}$, Huixian $\mathrm{Li}^{4+}$, Jiaqi Tong ${ }^{1 \dagger}$ and Mu Jin ${ }^{1,2^{*}}$ (D)

\begin{abstract}
Objective: The goal of this study was to analyze perioperative risk factors to predict one- year mortality after operation for acute type A aortic dissection (AAD).

Methods: A total of 121 consecutive patients undergoing Stanford type A AAD surgery in Beijing Anzhen Hospital were enrolled. Preoperative clinical and laboratory data from patients were collected.

Results: Multivariable Cox regression analysis showed that significant factors associated with increased one-year mortality were elder age (year) (hazard ratio (HR) 1.0985; 95\% confidence interval (CI) 1.0334-1.1677), intraoperative blood transfusion $\geq 2000 \mathrm{~mL}$ ( $\mathrm{HR} 8.8081 ; 95 \% \mathrm{Cl} 2.3319-33.2709$ ), a higher level of serum creatinine ( $\mu \mathrm{mol} / \mathrm{L}$ ) at postoperative one day (HR 1.0122; 95\% Cl 1.0035-1.0190) and oxygenation index $(\mathrm{Ol})<200(\mathrm{mmHg})$ at the end of surgery (HR 5.7575; 95\% Cl 1.1695-28.3458).

Conclusion: In this study, perioperative risk factors to predict one-year prognosis are age, intraoperative blood transfusion $\geq 2000 \mathrm{~mL}$, postoperative $\mathrm{Ol}<200 \mathrm{mmHg}$ and level of postoperative serum creatinine. The results aid in the comprehension of surgical outcomes and assist in the optimization of treatment strategies for those with perioperative risk factors to decrease one-year mortality.
\end{abstract}

Keywords: Acute type a aortic dissection, Short-term mortality, Perioperative risk factor

\section{Background}

Acute type-A aortic dissection (ATAAD) is a deadly cardiovascular event, and emergency surgery is typically indicated but associated with a 5-25\% mortality rate [1-3]. Several predictors of short-term adverse events in acute aortic dissection have been investigated, including age [4], female predispositions [5], prolonged mechanical ventilation [6], hypotension [7], and impaired renal function [8]. Our previous study showed that postoperative mortality was less than one year (6). Thus this investigation provides insights into the one-year mortality rate following an operation for ATAAD to analyze the perioperative risk factors that predict short-term mortality.

\section{Materials and methods}

The data used in this study were acquired from a previous clinical trial (ClinicalTrials.gov number: NCT01894334) [9], and the procedures were approved by the Beijing Anzhen Hospital Clinical Research Ethics Committee. Informed consent was obtained before surgery.

* Correspondence: jinmu0119@hotmail.com work.

${ }^{1}$ Department of Anesthesiology, Beijing Friendship Hospital, Capital Medical University, Beijing 100050, China

${ }^{2}$ Department of Anesthesiology, Beijing Anzhen Hospital, Capital Medical University, Beijing Institute of Heart Lung and Blood Vessel Diseases, and Beijing Engineering Research Center of Vascular Prostheses, Beijing 100029, China

Full list of author information is available at the end of the article

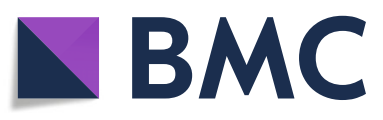

(c) The Author(s). 2020 Open Access This article is licensed under a Creative Commons Attribution 4.0 International License, which permits use, sharing, adaptation, distribution and reproduction in any medium or format, as long as you give appropriate credit to the original author(s) and the source, provide a link to the Creative Commons licence, and indicate if changes were made. The images or other third party material in this article are included in the article's Creative Commons licence, unless indicated otherwise in a credit line to the material. If material is not included in the article's Creative Commons licence and your intended use is not permitted by statutory regulation or exceeds the permitted use, you will need to obtain permission directly from the copyright holder. To view a copy of this licence, visit http://creativecommons.org/licenses/by/4.0/. The Creative Commons Public Domain Dedication waiver (http://creativecommons.org/publicdomain/zero/1.0/) applies to the data made available in this article, unless otherwise stated in a credit line to the data. 


\section{Patients}

All patients with ATAAD were enrolled in Beijing Anzhen Hospital between January 2013 to November 2014. ATAAD was defined as patients appearing with aortic dissection within two weeks of the onset of symptoms [10]. This study included patients aged 18 to 75 years diagnosed with ATAAD confirmed by computed tomography (CT) assisted angiography of aorta. Patients with severe coronary heart disease, severe cardiac tamponade, severe nervous system abnormalities, grossly incomplete medical record and patients died within $48 \mathrm{~h}$ after surgery were excluded. A total of 121 patients (93 men, 28 women) with a mean age of $46.6 \pm 10.4$ years were included in the final analysis.

\section{Surgical technique}

The surgical technique has been described in detail previously [6]. In brief, after cardiopulmonary bypass (CPB) was established, the surgical procedure involved the deployment of a frozen elephant trunk, Cronus (MicroPort Medical, Shanghai, China), into the descending aorta, followed by total arch replacement with a 4-branched vascular graft (Maquet Cardiovascular, Wayne, NJ). Aortic valve or root procedures and concomitant surgeries were performed during the cooling phase. Allogeneic red blood cells were transfused to maintain a post-CPB hemoglobin level $>7 \mathrm{~g} / \mathrm{L}$ and to correct coagulopathy after normalizing the thromboelastogram with fresh frozen plasma and platelets.

\section{Date collection}

The patient's profiles, such as age, gender, body mass index (BMI), smoking history (age commenced, age ceased, and average cigarettes smoked per day), hypertension history (age of onset and treatment), and diabetes history (age of onset and treatment), aortic diameter, left ventricular ejection fraction (LVEF), left ventricular end-diastolic dimension (LVEDd), were gathered from the case database. Perioperative clinical data from patients were also collected. Prolonged mechanical ventilation was defined as mechanical ventilation for more than $48 \mathrm{~h}$ after surgery.

\section{Statistical analysis}

This article is a reanalysis of data published previously $[6,11]$. Data analysis was performed using SPSS for windows, Version 18.0 (IBM, Armonk, NY, USA). Data was presented as mean \pm standard deviation (or median [interquartile range]) and groups were compared using a Student's $t$-test for normal distribution. Numbers (percentage) were compared using a Pearson chi-square or Fisher exact test. A Mann-Whitney U-test was performed for non-normal or skewed distributions. Cox proportional hazards models were used to compare the crude group with the adjusted group. Survival was assessed using the Kaplan-Meier method. All tests were two-sided, and statistical significance was set at $p<0.05$.

\section{Study endpoint}

The primary endpoint of this study was the risk factors for one-year mortality in patients with Acute Type-A Aortic Dissection.

\section{Results}

The flow diagram was present in Fig. S1. Total arch replacement and frozen elephant trunk implantation (FET) was successful in all 121 patients and a modified Bentall procedure was performed in 66 patients with severe aortic regurgitation. The perioperative clinical profiles of all 121 patients were shown in Table 1 . The in-hospital mortality rate was $6.6 \%(8 / 121)$ and overall postoperative one-year mortality was $9.9 \%(12 / 121)$. The patient life curves were shown in Fig. 1.

As shown in Table 1, the following variables differed significantly between the alive and death groups: years of age (Age, $p=0.0033$ ), preoperative platelet count (PLC, $p=0.0455$ ), preoperative serum lactate (LAC, $p=$ $0.0052)$, EuroSCOREII $(p=0.0357)$, duration of surgery $(p=0.0126)$, intraoperative transfusion of blood products $\geq 2000 \mathrm{~mL}(p=0.0074)$, postoperative heart rate $(p=$ $0.0132)$, postoperative serum lactate $(p=0.0012)$, oxygenation index at end of surgery $<200 \mathrm{mmHg}$ (OI, $p=$ $0.0494)$, postoperative $\operatorname{LVEF}(p=0.0064)$, postoperative serum creatinine $(p=0.0003)$, tracheotomy $(p=0.0245)$, continuous renal replacement therapy $(p=0.0233)$ and prolonged mechanical ventilation $(p=0.0048)$.

Elder patients (hazard ratio (HR) 1.0999; 95\% confidence interval (CI) 1.0334-1.1677; $p=0.0026$ ), or those that underwent intraoperative blood transfusion $\geq 2000$ mL (HR 8.8081; 95\% CI 2.3319-33.2709; $p=0.0013$ ), OI at the end of surgery $<200 \mathrm{mmHg}$ (HR 5.7575; 95\% CI $1.1695-28.3458 ; p=0.0314$ ) or had a higher level of serum creatinine at postoperative one day $(\mu \mathrm{mol} / \mathrm{L}, \mathrm{HR}$ 1.0112; 95\% CI 1.0035-1.0190; $p=0.0043$ ) had a higher risk of one-year mortality following surgery per Cox regression analysis (Table 2). The area under the receiver operating characteristic (ROC) curve was $0.906(p<$ 0.001 , Fig. 2), suggesting modest predictability. However, among patients with actual mortality of less than $40 \%$, the model overestimated mortality risk by $10 \%$ or greater (Fig. 3).

\section{Discussion}

ATAAD is a rapidly progressing catastrophic disease associated with high morbidity and mortality. In this single-center clinical trial, the one-year mortality was 9.9\%. This finding was consistent with the mortality presented in previous reports [12]. 
Table 1 Perioperative Clinical Profiles

\begin{tabular}{|c|c|c|c|c|c|c|}
\hline Variables & Total & Alive & Death & HR & $95 \% \mathrm{Cl}$ & $p$ Value \\
\hline \multicolumn{7}{|l|}{ Preoperative } \\
\hline Number $(n)$ & 121 & 109 & 12 & & & - \\
\hline Age (year) & $46.6 \pm 10.4$ & $45.7 \pm 9.9$ & $55.2 \pm 11.1$ & 1.0986 & $1.0318-1.1697$ & 0.0033 \\
\hline Males, $n(\%)$ & $93(77)$ & $84(77)$ & $9(75)$ & 0.8957 & $0.2425-3.3087$ & 0.8688 \\
\hline $\mathrm{BMI}\left(\mathrm{kg} / \mathrm{M}^{2}\right)$ & $25.9 \pm 3.2$ & $25.9 \pm 3.3$ & $25.3 \pm 2.7$ & 0.9375 & $0.7820-1.1239$ & 0.4852 \\
\hline History of smoking, n (\%) & $63(52)$ & $57(52)$ & $6(50)$ & 0.9001 & $0.2903-2.7912$ & 0.8554 \\
\hline History of hypertension, $n$ (\%) & $86(71)$ & $77(71)$ & $9(75)$ & 1.2185 & $0.3299-4.5012$ & 0.7669 \\
\hline Time from onset of symptoms to surgery (d) & $2.00(1.00-5.00)$ & $2.00(1.00-5.00)$ & $1.00(0.95-2.25)$ & 0.7173 & $0.4982-1.0328$ & 0.0740 \\
\hline Aortic diameter (mm) & $47.6 \pm 8.2$ & $47.2 \pm 7.9$ & $50.7 \pm 10.0$ & 1.0416 & $0.9816-1.1053$ & 0.1785 \\
\hline Hear rate (beats/min) & $77 \pm 15$ & $76 \pm 15$ & $78 \pm 15$ & 1.0103 & $0.9745-1.0474$ & 0.5779 \\
\hline $\mathrm{SBP}(\mathrm{mm} \mathrm{Hg})$ & $114 \pm 18$ & $113 \pm 18$ & $115 \pm 19$ & 1.0044 & $0.9736-1.0362$ & 0.7822 \\
\hline $\mathrm{DBP}(\mathrm{mm} \mathrm{Hg})$ & $57 \pm 12$ & $56 \pm 12$ & $59 \pm 16$ & 1.0277 & $0.9806-1.0771$ & 0.2541 \\
\hline LVEF (\%) & $63 \pm 9$ & $62 \pm 9$ & $64 \pm 6$ & 1.0236 & $0.9415-1.1130$ & 0.5843 \\
\hline LVEDd (mm) & $51 \pm 8$ & $52 \pm 8$ & $49 \pm 7$ & 0.9412 & $0.8560-1.0349$ & 0.2106 \\
\hline $\mathrm{HB}(\mathrm{g} / \mathrm{L})$ & $12.7 \pm 1.4$ & $12.8 \pm 1.4$ & $12.2 \pm 0.9$ & 0.7723 & $0.5246-1.1369$ & 0.1903 \\
\hline $\operatorname{PLC}\left(10^{9} / \mathrm{L}\right)$ & $175 \pm 69$ & $180 \pm 68$ & $132 \pm 52$ & 0.9897 & $0.9796-0.9998$ & 0.0455 \\
\hline WBC $\left(10^{9} / \mathrm{L}\right)$ & $9.5 \pm 3.5$ & $9.5 \pm 3.5$ & $9.3 \pm 2.6$ & 0.9909 & $0.8374-1.1726$ & 0.9156 \\
\hline LAC (mmol/L) & $1.00(0.80-1.30)$ & $0.90(0.80-1.30)$ & $1.55(1.00-2.17)$ & 1.4802 & $1.1239-1.9493$ & 0.0052 \\
\hline EurOSCOREII & $5.00(5.00-6.00)$ & $5.00(5.00-5.00)$ & $5.50(5.00-6.25)$ & 1.8392 & $1.0416-3.2476$ & 0.0357 \\
\hline \multicolumn{7}{|l|}{ Intraoperative } \\
\hline$B+S \cap(\%)$ & $66(54.55 \%)$ & $61(55.96 \%)$ & $5(41.67 \%)$ & 0.5943 & $0.1886-1.8726$ & 0.3742 \\
\hline$A+S n(\%)$ & $55(45.45 \%)$ & $48(44.04 \%)$ & $7(58.33 \%)$ & 1.6826 & $0.5340-5.3017$ & 0.3742 \\
\hline Duration of surgery (min) & $451 \pm 102$ & $443 \pm 97$ & $520 \pm 133$ & 1.0062 & $1.0013-1.0111$ & 0.0126 \\
\hline Duration of CPB (min) & $198 \pm 53$ & $196 \pm 51$ & $213 \pm 69$ & 1.0045 & $0.9959-1.0131$ & 0.3045 \\
\hline Cross clamp time (min) & $115 \pm 38$ & $114 \pm 39$ & $120 \pm 32$ & 1.0034 & $0.9900-1.017$ & 0.6212 \\
\hline Lowest rectal temperature $\left({ }^{\circ} \mathrm{C}\right)$ & $25.8 \pm 2.1$ & $25.8 \pm 2.1$ & $25.5 \pm 2.2$ & 0.9176 & $0.6861-1.2272$ & 0.5622 \\
\hline Allogeneic Red blood cells (units) & $2.00(0.00-4.00)$ & $2.00(0.00-4.00)$ & $4.00(1.50-6.25)$ & 1.2395 & $1.0465-1.4682$ & 0.0129 \\
\hline Blood transfusion $>2000 \mathrm{~mL}$ & $18(14.88)$ & $13(11.93)$ & $5(41.67)$ & 4.8038 & $1.5229-15.1534$ & 0.0074 \\
\hline \multicolumn{7}{|l|}{ End of surgery } \\
\hline Heart rate (beats/min) & $95 \pm 17$ & $94 \pm 16$ & $105 \pm 17$ & 1.0315 & $1.0065-1.0572$ & 0.0132 \\
\hline $\mathrm{SBP}(\mathrm{mmHg})$ & $117 \pm 15$ & $118 \pm 14$ & $114 \pm 17$ & 0.9805 & $0.9420-1.0206$ & 0.335 \\
\hline $\mathrm{DBP}(\mathrm{mmHg})$ & $62 \pm 11$ & $62 \pm 10$ & $61 \pm 15$ & 0.9917 & $1.0084-1.0481$ & 0.7680 \\
\hline$H B(g / L)$ & $10.1 \pm 1.9$ & $10.1 \pm 1.8$ & $10.5 \pm 2.5$ & 1.0806 & $0.8150-1.4327$ & 0.5901 \\
\hline $\operatorname{PLC}\left(10^{9} / \mathrm{L}\right)$ & $109 \pm 52$ & $112 \pm 54$ & $84 \pm 29$ & 0.9879 & $0.9743-1.0017$ & 0.0855 \\
\hline WBC $\left(10^{9} / L\right)$ & $11.2 \pm 4.4$ & $11.3 \pm 4.4$ & $10.0 \pm 3.5$ & 0.9330 & $0.8005-1.0874$ & 0.3748 \\
\hline $\mathrm{LAC}(\mathrm{mmol} / \mathrm{L})$ & $3.65(2.00-5.75)$ & $3.50(1.90-5.45)$ & $5.80(4.85-8.90)$ & 1.2738 & $1.1005-1.4744$ & 0.0012 \\
\hline $\mathrm{Ol}<200 \mathrm{mmHg}, n(\%)$ & $64(52.89)$ & $54(49.5)$ & $10(83.3)$ & 4.5814 & $1.0037-20.9106$ & 0.0494 \\
\hline \multicolumn{7}{|l|}{ Postoperative } \\
\hline Postoperative LVEF (\%) & $61 \pm 8$ & $61 \pm 7$ & $54 \pm 14$ & 0.9049 & $0.8421-0.9723$ & 0.0064 \\
\hline Serum creatinine $(\mu \mathrm{mol} / \mathrm{L})$ & $109 \pm 52$ & $104 \pm 44$ & $163 \pm 80$ & 1.0146 & $1.0067-1.0225$ & 0.0003 \\
\hline Neurological deficits, $n(\%)$ & $12(9.92 \%)$ & $9(8.26 \%)$ & $3(25.00 \%)$ & 3.4885 & $0.9436-12.8974$ & 0.0611 \\
\hline prolonged mechanical ventilation $n(\%)$ & $35(28.93 \%)$ & $27(24.77 \%)$ & $8(66.67 \%)$ & 5.6310 & $1.6932-18.7263$ & 0.0048 \\
\hline Reexploration for bleeding or debridement, $n(\%)$ & $11(9.09 \%)$ & $9(8.26 \%)$ & $2(16.67 \%)$ & 1.0932 & $0.1410-8.4735$ & 0.9321 \\
\hline Tracheotomy $n(\%)$ & $10(8.26 \%)$ & $7(6.42 \%)$ & $3(25.00 \%)$ & 4.4911 & $1.2135-16.6210$ & 0.0245 \\
\hline
\end{tabular}


Table 1 Perioperative Clinical Profiles (Continued)

\begin{tabular}{|c|c|c|c|c|c|c|}
\hline Variables & Total & Alive & Death & HR & $95 \% \mathrm{Cl}$ & $p$ Value \\
\hline CRRT $n(\%)$ & $5(4.13 \%)$ & $3(2.75 \%)$ & $2(16.67 \%)$ & 5.8043 & $1.2696-26.5370$ & 0.0233 \\
\hline
\end{tabular}

Marfan syndrome was the causative and exclusively factored in younger patients. In contrast, arterial hypertension and atherosclerosis were the causes in elderly patients [13, 14]. Affected by long-term hypertension and progressive atherosclerosis, the elderly and young people have different pathological and pathogenic mechanisms in the development of acute aortic dissection [15, 16]. In the present investigation, we also found that as age increases, so does the mortality rate. Although our study population is relatively young compared to previous studies, we still think the results may be related to the difference in the aforementioned pathogenic factors (such as hypertension and atherosclerosis) in recent years. In addition to hypertension and underlying connective tissue disorders, systemic pathological changes also result in end-organ damage such as chronic renal dysfunction. Importantly, each of these factors increases the risk of anesthesia, surgery, and postoperative mortality.

Serum creatinine is an important indicator of renal function. In our study, postoperative hyperphosphatemia creatinine suggests the possibility of postoperative renal injury. Patients with postoperative renal injury have more extended hospital stays, longer postoperative

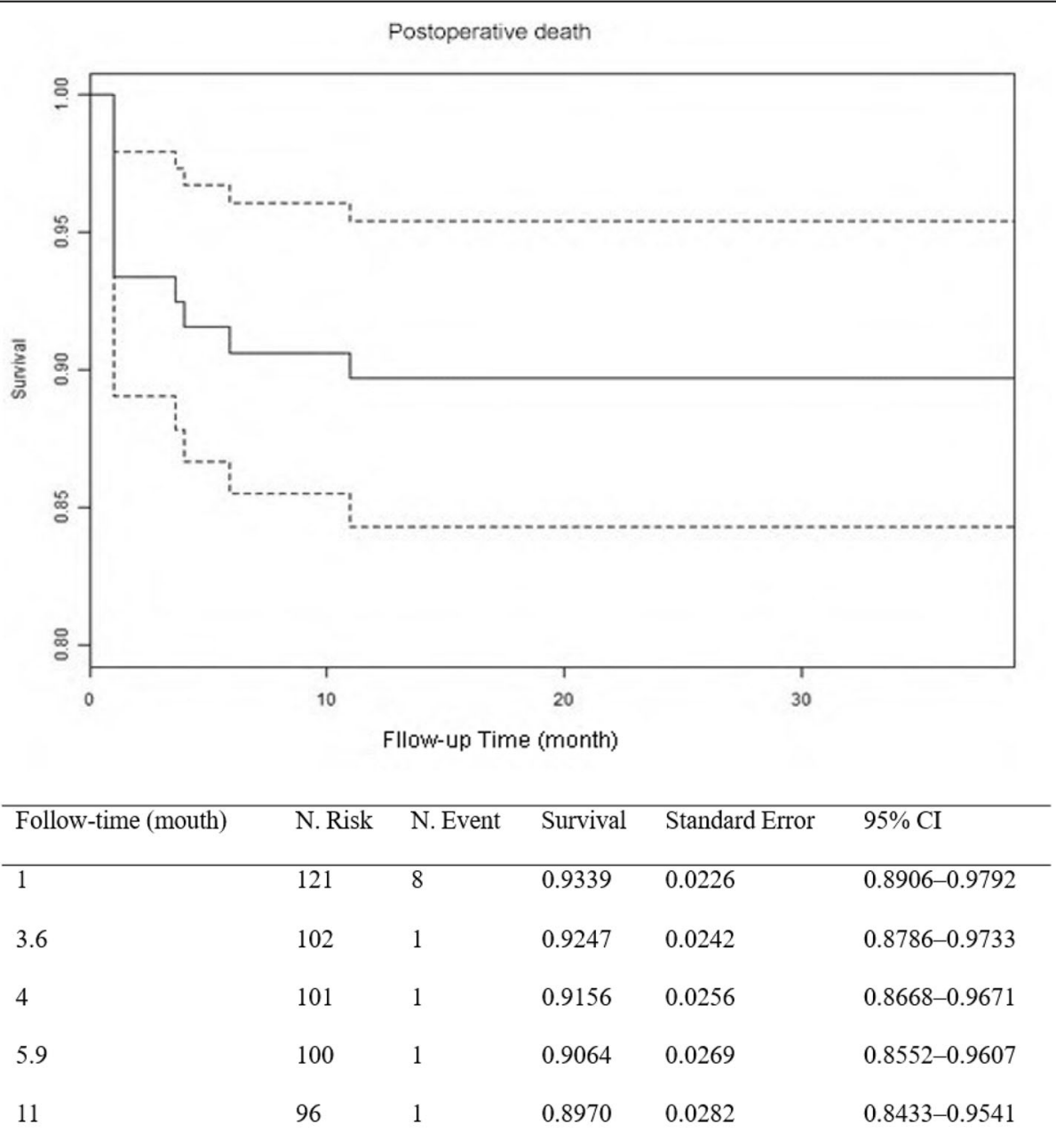

Fig. 1 Kaplan-Meier survival in patients with Acute type-A aortic dissection (ATAAD) repair 
Table 2 Risk Factors for One-year Mortality after Repair of Acute Type A Aortic Dissection

\begin{tabular}{|c|c|c|c|c|c|c|}
\hline \multirow[t]{2}{*}{ Variables } & \multicolumn{3}{|l|}{ Crude } & \multicolumn{3}{|c|}{ Adjusted $^{*}$} \\
\hline & HR & $95 \% \mathrm{Cl}$ & $p$ Value & HR & $95 \% \mathrm{Cl}$ & $p$ Value \\
\hline Age (year) & 1.0985 & $1.0334-1.1677$ & 0.0026 & 1.0985 & $1.0334-1.1677$ & 0.0026 \\
\hline Intraoperative Blood transfusion > $2000 \mathrm{~mL}$ & 8.8081 & $2.3319-33.2709$ & 0.0013 & 8.8081 & $2.3319-33.2709$ & 0.0013 \\
\hline Serum creatinine $(\mu \mathrm{mol} / \mathrm{L})$ at postoperative one day & 1.0112 & $1.0035-1.0190$ & 0.0043 & 1.0112 & $1.0035-1.0190$ & 0.0043 \\
\hline $\mathrm{Ol}<200(\mathrm{mmHg})$ at the end of suegery & 5.7575 & $1.1695-28.3458$ & 0.0314 & 5.7575 & $1.1695-28.3458$ & 0.0314 \\
\hline
\end{tabular}

Abbreviations: $\mathrm{Cl}$ confidence interval, $H R$ hazard ratio, $\mathrm{Ol}$ oxygenation index;

${ }^{*}$ Adjusted for time from symptom onset to surgery, duration of surgery, delayed extubation, preoperative LAC, postoperative neurological complications, preoperative platelet count and EuroSCOREII

ventilator support time, and even increased mortality $[17,18]$. The extension of the aortic dissection may involve renal ischemia or renal infarction on one or both sides of the renal artery, ultimately leading to renal insufficiency or kidney failure [19, 20]. Non-fluctuating perfusions and activation of inflammatory reactions during the extracorporeal circulation also lead to postoperative renal injury [21, 22].

Recent studies have shown that preoperative hypoxemia $(\mathrm{HO})$ is an independent risk factor for acute lung injury (ALI) in patients with ATAAD [6]. Studies have shown that postoperative ALI will Prolonged mechanical ventilation, ICU and hospital stay [23]. It has also been reported that 5.3 to $16.7 \%$ of patients with ATAAD die from multiple organ dysfunction characterized by acute respiratory failure [24]. Postoperative patients are more prone to acute respiratory distress syndrome, decreased oxygenation index, increased postoperative ventilator use time, and increased ventilator-related pulmonary complications, which may be one of the reasons for the high shortterm mortality rate [6].

AAD is characterized by the rapid development of an intimal flap separating the true and false lumen, blood flow through the non-endothelialized false lumen, tissue damage, and turbulence, each of which triggers coagulation. During surgery, CPB-induced coagulopathy, platelet activation and dysfunction and promoted coagulation factor consumption and excessive fibrinolysis [25, 26]. Therefore, patients undergoing surgery for AAD bleed

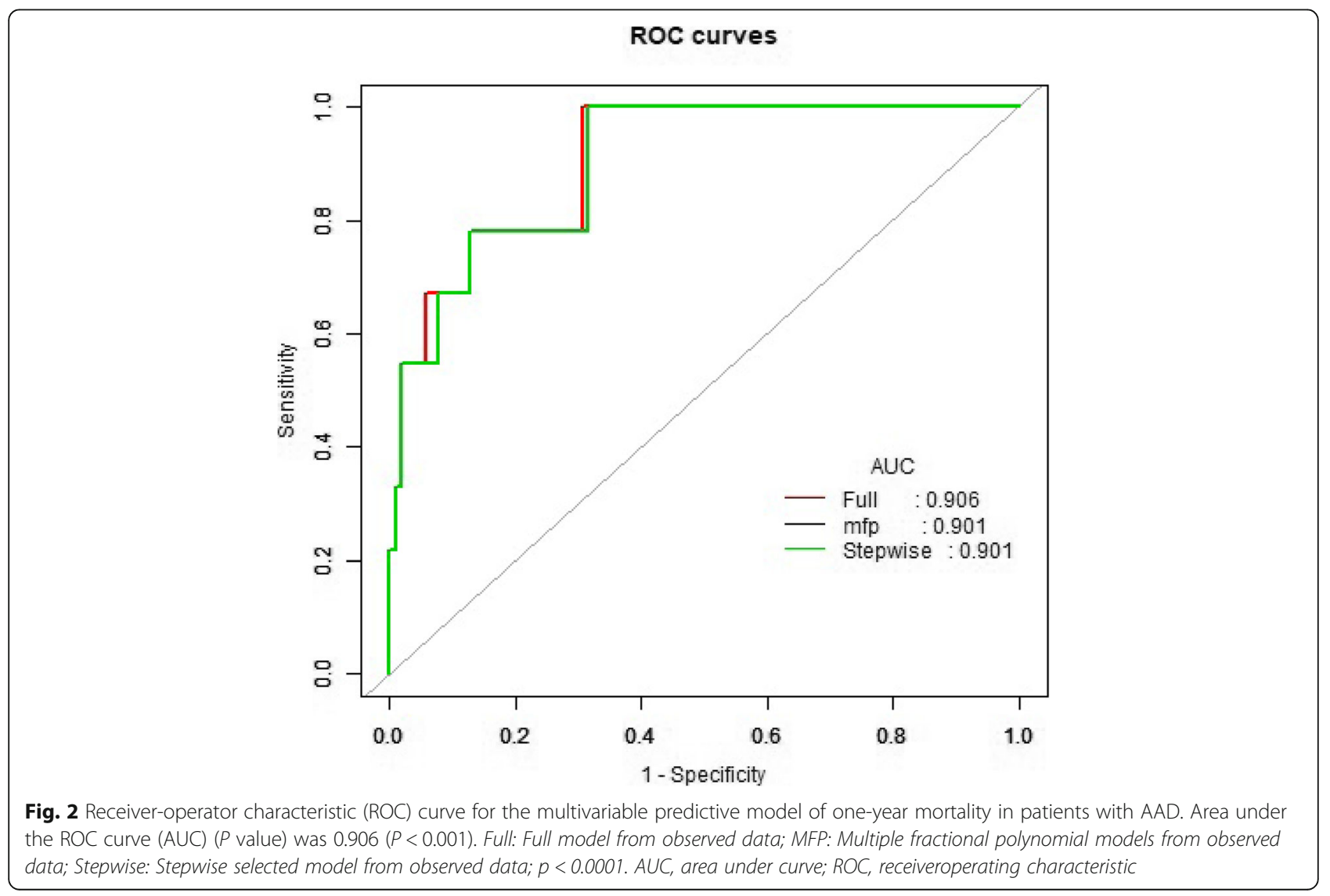




\section{Calibration curve} Stepwise

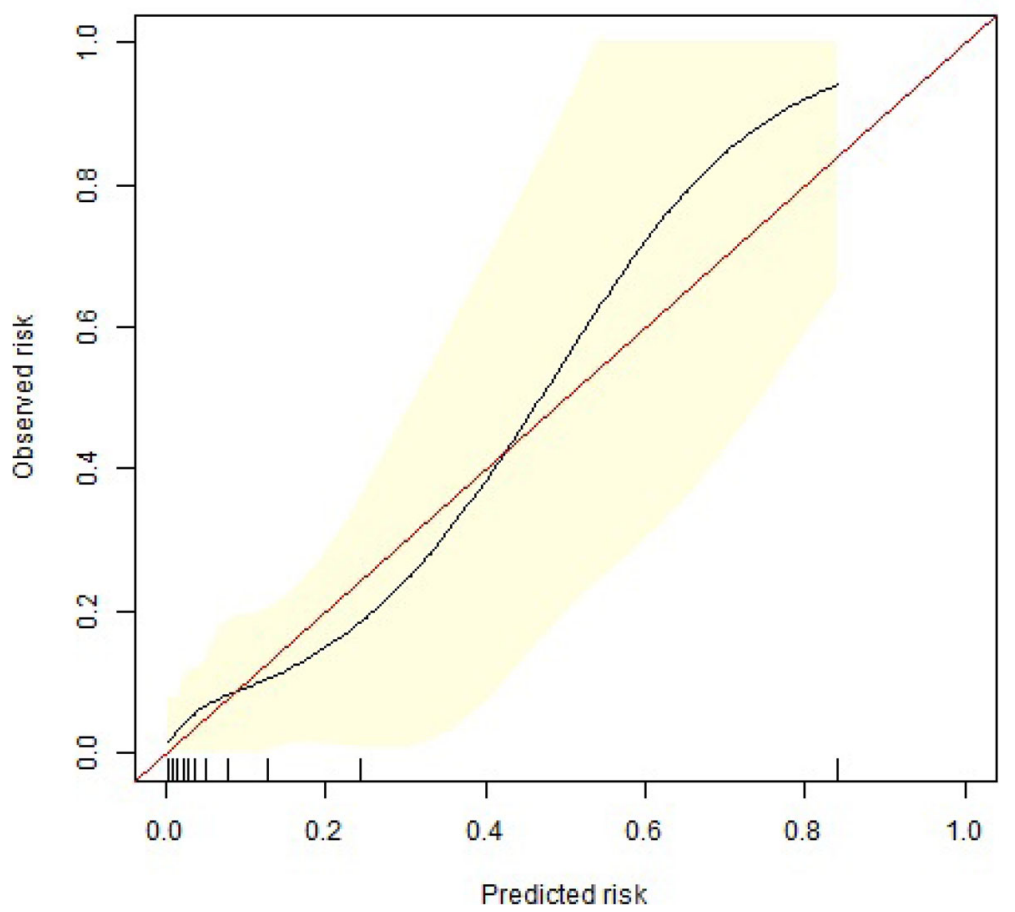

Fig. 3 Calibration curve showing the predicted mortality risk against the observed one-year mortality risk in the overall cohort. Among patients with actual mortality of less than $40 \%$, the model overestimated mortality risk by $10 \%$ or greater

excessively and require blood products and transfusions, which is the primary cause of surgical- mortality [27]. In our study, a large number of blood transfusions $(\geq 2000$ $\mathrm{ml}$ ) during surgery is also a risk factor for postoperative one-year mortality.

\section{Study limitations}

This study had three limitations. First, this trial was a retrospective analysis of prospectively collected data, and all inherent biases of retrospective analysis are inevitable. Second, all of the patients in our study were suitable for emergency AAD surgery without severe malperfusion and unstable hemodynamics and also excluded two patients who died within $48 \mathrm{~h}$ due to surgical procedure. The results of our cohort study might be more reflective of our clinical experience. Third, among some individuals with actual mortality of less than $40 \%$, the model might overestimated mortality risk by $10 \%$. Therefore, the use of the model may lead some patients to inappropriately overestimated mortality risk.

\section{Conclusions}

In the study of ATAAD, there were several factors associated with higher one-year mortality, including elder age, intraoperative blood transfusion $\geq 2000 \mathrm{~mL}$, postoperative $\mathrm{OI}<200 \mathrm{mmHg}$ and a higher level of postoperative serum creatinine. The results of our study aid in the comprehension of surgical outcomes and assist in the optimization of treatment strategies for those with perioperative risk factors to decrease short-term mortality.

\section{Supplementary information}

Supplementary information accompanies this paper at https://doi.org/10. 1186/s13019-020-01296-8.

Additional file 1. Figure S1. Flow diagram

\section{Abbreviations \\ Abbreviated: Full Name; AAD: Acute Aortic Dissection; ATAAD: Acute type-A aortic dissection; CT: Computed Tomography; CPB: CardiopulmonaryBypass; BMI: BodyMass Index; LVEF: Left Ventricular Ejection Fraction; LVEDd: Left Ventricular End-diastolic Dimension; FET: Frozen Elephant Trunk; A + S: Ascending Aorta Aeplacement + Sun's Procedure; B + S: Bentall + Sun's Procedure; Cl: Confidence Interval; CRRT: Continuous Renal Replacement Therapy; DBP: Diastolic Blood Pressure; SBP: Systolic Blood Pressure; HB: Hemoglobin; LAC: Lactate; Ol: Oxygenation Index; PLC: Preoperative Platelet Coun; WBC: White Blood Cells; HO: Preoperative Hypoxemia; ALI: Acute Lung Injury}

\section{Acknowledgments}

We thank LetPub (www.letpub.com) for its linguistic assistance during the preparation of this manuscript. 


\section{Authors' contributions}

MJ was responsible for the original idea, which was co-developed by all authors. All authors (YWY, JYX, HXL, JQT and MJ) developed the conception and design of this manuscript. YWY, JYX, KXL and JQT validated the provision of study materials or patients and carried out all the data management and statistical analyses, which was supervised by MJ. MJ was responsible for writing the manuscript, which was critically revised by all co-authors. The authors read and approved the final manuscript.

\section{Funding}

This study was supported by grants from the Beijing Major Science and Technology Projects from Beijing Municipal Science and Technology Commission (No.Z171100001017083). Sponsors did not influence the design, analysis, or publication of this study.

\section{Availability of data and materials}

The dataset used and analyzed during the current study is available from the corresponding author upon reasonable request.

\section{Ethics approval and consent to participate}

This study was in agreement with the guidelines of the Ethics Committee of the Beijing Anzhen hospital.

\section{Consent for publication}

All patients gave verbal and written informed consent prior to enrollment.

\section{Competing interests}

The authors declare that they have no competing interests.

\section{Author details}

'Department of Anesthesiology, Beijing Friendship Hospital, Capital Medical University, Beijing 100050, China. ${ }^{2}$ Department of Anesthesiology, Beijing Anzhen Hospital, Capital Medical University, Beijing Institute of Heart Lung and Blood Vessel Diseases, and Beijing Engineering Research Center of Vascular Prostheses, Beijing 100029, China. ${ }^{3}$ Department of Anesthesiology, Guangzhou Women and Children's Medical Center, Guangzhou, China. ${ }^{4}$ Department of Anesthesiology, The First Hospital of Tsinghua University, Beijing, China.

Received: 4 July 2020 Accepted: 3 September 2020

Published online: 11 September 2020

\section{References}

1. Lauterbach SR, Cambria RP, Brewster DC, Gertler JP, LaMuraglia GM, Isselbacher EM, et al. Contemporary management of aortic branch compromise resulting from acute aortic dissection. J Vasc Surg. 2001;33: 1185-92.

2. Pacini D, Di Marco L, Fortuna D, Belotti LMB, Gabbieri D, Zussa C, et al. Acute aortic dissection: epidemiology and outcomes. Int J Cardiol. 2013;167: 2806-12.

3. Clough RE, Nienaber CA. Management of acute aortic syndrome. Nat Rev Cardiol. 2015;12:103-14.

4. Rylski B, Hoffmann I, Beyersdorf F, Suedkamp M, Siepe M, Nitsch B, et al. Acute aortic dissection type a: age-related management and outcomes reported in the german registry for acute aortic dissection type a (geraada) of over 2000 patients. Ann Surg. 2014;259:598-604.

5. Nienaber CA, Fattori R, Mehta RH, Richartz BM, Evangelista A, Petzsch M, et al. Gender-related differences in acute aortic dissection. Circulation. 2004; 109:3014-21.

6. Jin M, Ma WG, Liu S, Zhu J, Sun L, Lu J, et al. Predictors of prolonged mechanical ventilation in adults after acute type-a aortic dissection repair. J Cardiothorac Vasc Anesth. 2017;31:1580-7.

7. Howard DPJ, Banerjee A, Fairhead JF, Perkins J, Silver LE, Rothwell PM. Population-based study of incidence and outcome of acute aortic dissection and premorbid risk factor control: 10-year results from the oxford vascular study. Circulation. 2013;127:2031-7.

8. Zhang J, Jiang Y, Gao C, Feng J, Wang A. Risk factors for hospital death in patients with acute aortic dissection. Heart Lung Circ. 2015;24:348-53.

9. Cheng $Y$, Jin $M$, Dong $X$, Sun $L$, Liu J, Wang $R$, et al. Mechanism and early intervention research on ali during emergence surgery of Stanford type-a aad: study protocol for a prospective, double-blind, clinical trial. Medicine. 2016;95:e5164.

10. Golledge J, Eagle KA. Acute aortic dissection. Lancet. 2008;372:55-66.

11. Pan X, Lu J, Cheng W, Yang Y, Zhu J, Jin M. Independent factors related to preoperative acute lung injury in 130 adults undergoing Stanford type-a acute aortic dissection surgery: A single-center cross-sectional clinical study. J Thor Dis. 2018;10:4413-23.

12. Santini F, Montalbano G, Casali G, Messina A, lafrancesco M, Battista Luciani $\mathrm{G}$, et al. Clinical presentation is the main predictor of in-hospital death for patients with acute type a aortic dissection admitted for surgical treatment: a 25 years experience. Int J Cardiol. 2007;115:305-11.

13. Li Y, Li L, Mu HS, Fan SL, He FG, Wang ZY. Aortic dissection and sudden unexpected deaths: a retrospective study of 31 forensic autopsy cases. Forensic Sci. 2015;60:1206-11.

14. Dean JH, Woznicki EM, O'Gara P, Montgomery DG, Trimarchi S, Myrmel T, et al. Cocaine-related aortic dissection: lessons from the international registry of acute aortic dissection. Am J Med. 2014;127:878-85.

15. Pomianowski $P$, Elefteriades JA. The genetics and genomics of thoracic aortic disease. Ann Cardiothorac Surg. 2013;2:271-9.

16. Bee KJ, Wilkes DC, Devereux RB, Basson CT, Hatcher CJ. Tgfßriib mutations trigger aortic aneurysm pathogenesis by altering transforming growth factor $\beta 2$ signal transduction. Circ Cardiovasc Genet. 2012;5:621-9.

17. Parolari A, Pesce LL, Pacini D, Mazzanti V, Salis S, Sciacovelli C, et al. Risk factors for perioperative acute kidney injury after adult cardiac surgery: role of perioperative management. Ann Thorac Surg. 2012;93:584-91.

18. Yacoub R, Patel N, Lohr JW, Rajagopalan S, Nader N, Arora P. Acute kidney injury and death associated with renin angiotensin system blockade in cardiothoracic surgery: a meta-analysis of observational studies. Am J Kidney Dis. 2013;62:1077-86.

19. Imasaka K, Tayama E, Tomita Y. Preoperative renal function and surgical outcomes in patients with acute type a aortic dissection. Interact Cardiovasc Thorac Surg. 2015;20:470-6.

20. Roh GU, Lee JW, Nam SB, Lee J, Choi JR, Shim YH. Incidence and risk factors of acute kidney injury after thoracic aortic surgery for acute dissection. Ann Thorac Surg. 2012;94:766-71.

21. Tsai HS, Tsai FC, Chen YC, Wu LS, Chen SW, Chu JJ, et al. Impact of acute kidney injury on one-year survival after surgery for aortic dissection. Ann Thorac Surg. 2012;94:1407-12.

22. Piffaretti G, Mariscalco G, Bonardelli S, Sarcina A, Gelpi G, Bellosta R, et al. Predictors and outcomes of acute kidney injury after thoracic aortic endograft repair. J Vasc Surg. 2012;56:1527-34.

23. Matthay MA, Zemans RL. The acute respiratory distress syndrome: pathogenesis and treatment. Annu Rev Pathol. 2011;6:147-63.

24. Luo F, Zhou XL, Li JJ, Hui RT. Inflammatory response is associated with aortic dissection. Ageing Res Rev. 2009;8:31-5.

25. Zindovic I, Sjogren J, Bjursten $H$, Bjorklund $E$, Herou $E$, Ingemansson $R$, et al. Predictors and impact of massive bleeding in acute type a aortic dissection. Interact Cardiovasc Thorac Surg. 2017;24:498-505.

26. Pan X, Lu J, Cheng W, Yang Y, Zhu J, Jin M. Pulmonary static inflation with $50 \%$ xenon attenuates decline in tissue factor in patients undergoing Stanford type a acute aortic dissection repair. J Thor Dis. 2018;10:4368-76.

27. Zheng J, Wu Y, Li Z, Wang H, Xiao W, Shi Y, et al. Low serum total bilirubin concentration was associated with increased high sensitive $c$ reactive protein level in patients with impaired glucose tolerance and type 2 diabetes mellitus subjects. Clin Lab. 2016:62:901-7.

\section{Publisher's Note}

Springer Nature remains neutral with regard to jurisdictional claims in published maps and institutional affiliations. 